\title{
THE
}

2010

\section{Toward linking ocean models to fish population dynamics}

Lawrence J. Buckley

University of Rhode Island

Lauren B. Buckley

Follow this and additional works at: https://digitalcommons.uri.edu/gsofacpubs

This is a pre-publication author manuscript of the final, published article.

Creative Commons License

(c) $($ i) $\Theta$

This work is licensed under a Creative Commons Attribution-Noncommercial-No Derivative Works 4.0 License.

\section{Citation/Publisher Attribution}

Buckley, L. J., \& Buckley, L. B. (2010). Toward linking ocean models to fish population dynamics. Progress in Oceanography, 84(1-2), 85-88. doi: 10.1016/j.pocean.2009.09.009

Available at: https://doi.org/10.1016/j.pocean.2009.09.009

This Article is brought to you for free and open access by the Graduate School of Oceanography at DigitalCommons@URI. It has been accepted for inclusion in Graduate School of Oceanography Faculty Publications by an authorized administrator of DigitalCommons@URI. For more information, please contact digitalcommons-group@uri.edu. 


\title{
Toward linking ocean models to fish population dynamics
}

\author{
Lawrence J. Buckley ${ }^{\mathrm{a}, ~}$ and Lauren B. Buckley ${ }^{\mathrm{b}, 1}$
}

\footnotetext{
a University of Rhode Island, Graduate School of Oceanography, South Ferry Road, Narragansett, RI 02835, USA

${ }^{b}$ National Center for Ecological Analysis and Synthesis, Santa Barbara, CA 93101, USA

${ }^{1}$ Present address: CB\# 3280, Coker Hall, The University of North Carolina at Chapel Hill, Chapel Hill, NC 27599-3280, USA.
}

* Corresponding author : Lawrence J. Buckley, Tel.: +1 401874 6671; fax: +1 401782 3201, email address : lbuckley@gso.uri.edu

\begin{abstract}
:
We discuss Lehodey et al.'s (2009) approach to linking ocean models to population dynamics of large marine predators, consider its benefits and limitations, and outline alternative approaches. We advocate a middle ground between Lehodey et al.'s pragmatic, phenomenological approach and the detailed mechanistic approach common to most individual based models. These models should capture the essence of critical processes controlling recruitment and dynamic density-dependent and environmental effects.
\end{abstract}


Patrick Lehodey's (this volume) presentation was one of two visionary talks under the heading "Zooplankton Fish Coupling" and the only paper in Section 5 "Forage control on predator dynamics". Interestingly, while Lehodey's (this volume) modeling efforts span most of the topics considered over the course of the meeting, the paper published in these proceedings is more limited in scope than his presentation and initial submission. The manuscript describes an approach to modeling the dynamics of mid trophicfunctional groups that sets the stage for considering "Forage control on predator dynamics". In this comment we consider the original manuscript, presentation, and discussions at the meeting, the revised manuscript that appears in the proceedings, the larger body of Lehodey's published manuscripts, and other relevant papers.

Lehodey et al. (this volume) step into a wide breach between the relatively advanced coupled ocean-general-circulation and biogeochemical models (OGBCM) and the relatively well documented dynamics of top pelagic predators. In between these two ends of the pelagic food web are the mid-trophic level (MTL) organisms that for the most part are little studied and poorly understood. Lehodey et al. (this volume) take a practical and pragmatic approach to modeling these mid-trophic levels, linking the output of an OGBCM to pelagic predator dynamics. While the results are very promising, they are working in a very data poor part of the world ocean and many of their findings are difficult to test against actual data.

This work also is significant in that it represents one of the first implementations of the "rhomboid approach" to modeling ecosystem dynamics (de Young et al. 2004). The "rhomboid approach" advocates concentration of biological detail at the level of interest with decreasing detail up and down the trophic scale from that level and the inclusion of uncertainty. Lehodey et al., (this volume) primary interest is in the top pelagic predators, so the MTL are treated in much less detail, aggregated into groups based on position in the water column rather than taxonomy or physiology. If the species of interest are the large pelagic predators, how much detail is needed in the mid-trophic levels?

In the gradient between mechanistic and phenomenological models (Schoener 1986, Koehl 1989), Lehodey et al., (this volume) model falls toward the phenomenological. In many instances, rather than capturing the dynamics of underlying processes, their model relies on statistical descriptions of the patterns that emerge from these processes without explicitly representing the underlying processes. The success of phenomenological models relies on constancy in the processes that produce the described pattern. Environmental change is likely to drive deviations from this assumption, lending imperative to developing more mechanistic approaches. For example, their treatment of recruitment is largely descriptive (Lehodey et al. 2003), using a spawning habitat index that incorporates the ratio between food and predators of earlylife stages, and temperature. Parameterization of this simple model relies on a fit to available data and the approach assumes that the relations among food, predators and temperature will remain fixed in a changing environment.

A changing global climate and increased human disruption of marine systems have the potential to fundamentally alter the dynamics of marine systems (Jackson et al. 2001; Myers et al. 2007). Changes in ocean circulation have the potential to alter the transport of larvae and nutrients; changes in water temperature have the potential to alter reproduction and growth rates; and declines in populations of marine predators due to fishing are likely to alter marine food webs. Modeling and predicting the repercussions of these environmental changes requires a more fundamental and 
mechanistic understanding of the population and community dynamics of marine systems.

Many fish population models rely on statistically estimated parameters such as survival, mortality, and development time that are likely to shift in complex ways in response to environmental changes. A first principles approach to population and community dynamics is thus of increasing imperative. The emerging field of metabolic ecology offers promise for using energy to integrate across scales of ecological organization as energy is a fundamental currency across individuals, populations, and communities (Kleiber 1932, Calder 1984, Brown et al. 2004). Further, processes at each scale often optimize the acquisition or partitioning of energy.

One approach to understanding how the environment determines the energetics of individuals is coupled biophysical individual-based models (IBM). These bottom-up models incorporate detailed physiological-based descriptions of how the underlying environment constrains the growth of individual fish (e.g. Lough et al. 2006; Kristiansen et al. 2007). The complexity of these models can become prohibitive in scaling up to population and community dynamics. Lehodey et al. (this volume) present an alternative approach that relies on energetic scaling to describe the implications of the environment on population dynamics. Energetic scaling aggregates metabolic costs of individuals across levels of organization to understand the mass and temperature dependence of biological rates (Brown et al. 2004). While the optimal partitioning of energy, assumed in energetic scaling, is a powerful tool for simplifying models, the neglected behavioral details can prove essential to understanding marine population and community dynamics.

Lehodey et al. (this volume) model initiates with output from an OGBCM which serves to indicate how the environment constrains energy flow into the marine ecosystem. Their modeling of this energy flow through the pelagic ecosystem relies on estimated ecological transfer coefficients, to translate this primary production into biomass of zooplankton and micronekton. They functionally classify these mid-tropic groups based on position in the water column and diel movement. While they discuss using quarterpower scaling laws and allometric relationships to relate body size and water temperature to metabolic rate, no body mass term is used. They justify this omission by reference to the relatively small size difference among micronekton. Production is allocated to each of 6 MTL functional groups using an energy transfer matrix based in part on a fit to the sparse data available on the distribution of micronekton in the equatorial Pacific. During each time step the $6 \mathrm{MTL}$ functional groups and their prerecruits are subject to horizontal and vertical movement using advection-diffusion equations.

According to energetic scaling, the population turnover of these mid trophic groups should vary with an exponential effect of environmental temperature, as organisms require exponentially more energy for metabolism with increasing temperatures (Savage et al. 2004). Lehodey et al. (this volume) do not actually use this scaling principle to estimate rates of population turnover, but empirically fit a regression to describe how the age at maturity varies with environmental temperature (their Figure 2). They note that this empirically derived relationship scales as predicted by metabolic theory (Brown et al. 2004) and that energetic scaling could be used to derive these parameters for species with less empirical data available. 
Lehodey et al. (this volume) translate energy derived from consuming organisms in these mid trophic-groups to the population dynamics of predators using models developed earlier. Two additional models are critical to this effort, a spatial environmental population dynamics model (SEAPODYM) and a statistical population dynamics model (MULTIFAN-CL) (Lehodey et al. 2003). In several critical areas (e.g. total biomass and mortality-at-age of predators) SEPODY is constrained by or parameterized with output from MULTIFAN-CL. At times, it is difficult to determine just how independent SEAPODYM output is from MULTIFAN-CL input.

Lehodey et al. (this volume) modeling approach and presumably their view of the Pacific Ocean pelagic ecosystem appears to be "bottom up" with mid-tropic level prey treated as several generic boxes (functional groups) occupying different vertical zones. This treatment is justified by the "myriad of species providing forage for larger predators" and is in stark contrast to the "wasp-waist" structure "where a single species, or at most several species of small planktivorous fishes entirely dominate their trophic level" (Bakun 2006), resulting in "boom-bust" dynamics of these populations. These systems are characterized by middle-out control where the "boom-bust" cycles at mid-trophic levels reverberate through lower and higher trophic levels. When considering the entire tropical and temperate Pacific the "myriad of species" view is justified but when considering regional ecosystems, particularly the highly productive regions of the world oceans that account for the majority of the global fishery yield, the view is quite different. These include the western boundary currents were a single species may dominate its trophic level (e.g. Sardinops sagax in the Kuroshio region) or the various upwelling systems, such as the Canary Current system, where a relatively few species dominate the mid-trophic levels.

It should be possible to imbed more detailed regional models that capture more of the "wasp-waist" nature of certain key MTL organisms, into the larger basin-scale grid necessary for modeling the dynamics of wide ranging species such as some of the tunas. The benefits of this approach would have to be balanced against the increased complexity and computer resources necessary for implementation.

The question arose in this session and others; does biology have any rules or laws? One answer is that the rules are the rules of physics and chemistry and that biology is about finding ways to exploit or get around the rules, much the way a yacht designer might draw a distorted hull to exploit a measurement handicapping rule or an accountant may find a loophole in the tax laws. Bakun and Broad (2003) argue that environmental "loopholes" are critical to understanding fish population dynamic, using the sardine as an example of a species group that exploits the reduced productivity associated with El Nino events in the Peru-Humboldt, California Current and other regional ecosystems by migrating, feeding and spawning over great distances, where in certain areas reduced predation on their early-life stages results in major population expansions. The characteristics of the sardine that allow it to exploit these reduced productivity conditions are a high-fecundity, batch-spawning reproductive strategy and the ability to feed on small particles.

Given the importance of "loopholes" and the adaptations of individual species, scaling laws and allometric relationships may not adequately describe the performance or dynamics of any given species or even the aggregate, considering that each species has found its own unique way to live within the rules. Nevertheless, when life stages and species are aggregated into functional groups, metabolism, growth and other vital rates 
should approach those predicted by the scaling laws, since they arose in the first place from statistical fits to empirical data on a large number of species.

When we aggregate species into functional groups much of the biology is lost, but the hope is that the loss of detail will not distort the big picture at the level of the top predators. Lehodey et al. (this volume) treatment of the mid-trophic levels is straight forward. They assume that on average there are 2.5 trophic transfers between primary producers and carnivorous fish and squids (the mid-trophic levels) and that trophic efficiency at each level is 0.1 for total primary production for an overall transfer efficiency of 0.003 . While this conversion is immediate after each primary production input there is a temperature dependant delay before recruitment to mid-tropic levels. Empirical fits to available data were used to determine the minimum age (days) to recruitment in the midtrophic functional population $\left(\mathrm{t}_{\mathrm{r}}\right)$, the mortality coefficient $(\lambda)$, and the mean age of the population $\left(t_{r}+1 / \lambda\right)$ as a function of temperature. It was unclear how $t_{r}$

was estimated from development time $\left(t_{d}\right)$ the age at maturity plotted in Figure 2. Undoubtedly, all these parameters vary on a variety of spatial and temporal scales and, in addition to temperature, are affected by a variety of biotic and abiotic factors and their interactions. These dynamics are not captured in the current model. Also in there model $\lambda$ is uncoupled from predator density; i.e. there is no feedback of predator density on prey abundance.

Modeling benefits from and is constrained by the availability of data. While the area under consideration is expansive and data poor in general, there are several data needs that standout. Relatively little information is available on the abundance, distribution, and diel movements of MTL organisms in the central Pacific. The length of the trophic chain and transfer efficiency between primary producers and the MTLs, likely highly variable in space and time, are poorly known but critical to estimating the energy available to higher trophic levels. There are little data on the early-life stages of tunas and other important fish species, including mortality and growth rates in relation to environmental variability.

Given the huge domain under consideration, certain technologies such as acoustics and stable isotope analysis, which are amenable to broad-area coverage or integrate over space and time, offer a way forward to acquire the data needed to test, constrain and improve these models. GLOBEC type studies, focusing on the full-life cycle of target species and their physical and biotic environment, although necessarily limited in spatial coverage, should greatly assist in revealing and testing mechanistic linkages.

How is forage control of predator dynamics implemented in the Lehodey et al. (this volume) model? The answer to this question is most explicitly found in an earlier publication (Lehodey et al. 2003) describing an application of their modeling approach to skipjack tuna in the Pacific Basin. In the earlier effort tuna forage (F) was modeled as a single population integrated over all vertical layers rather than 6 components (the MTL organisms) as in the present paper. Lehodey et al. (2003) view recruitment as "the fundamental process that drives population biomass variability of tropical tunas". A spawning habitat index $\left(\mathrm{H}_{\mathrm{s}}\right)$ was used to "constrain the recruitment to environmental conditions". The number of recruits in a grid point is the product of $\mathrm{H}_{\mathrm{s}}$ and a recruitment scaling value $\left(R_{s}\right)$, used to scale total biomass to estimates from the MULTIFAN-CL model. Primary production $(P)$ is used as a proxy for the food available to larval and juvenile tunas, while tuna forage (F or MTL) is used as a proxy for their predators during the early-life stages. The spawning habitat index was calculated from the equation: 


$$
H_{s}=\theta_{s} e^{(\alpha \ln \Pi)}
$$

where $\theta_{s}$ is a temperature function, $\alpha$ is a scalar and $\Pi$ is the product of other effects in this case $\mathrm{P}$ and $1 / \mathrm{F}$. So, recruitment and therefore predator dynamics are treated as a function of temperature and the trade off between prey and predators.

Interestingly, the trade off between prey and predators on early life stages is central to Bakun and Broad's 2003 idea that 'loopholes' in biological constraints (predation pressure) may result in remarkable reproductive success for some species. A refinement to Lehodey et al. (this volume) spawning habitat index would be the addition of a scalar to weight the importance $P$ relative to $F$ or MTL for different species. Some species such as the sardine appear to be able to exploit situations where both $\mathrm{P}$ and $\mathrm{F}$ or MTL are low, while others (certain anchovy species) appear to require high $\mathrm{P}$. This translation of prey consumed into offspring is likely to vary with temperature. A mechanistic description of the temperature dependence of prey consumption and conversion into offspring would likely benefit the predictive power of the model.

A very different modeling approach where community structure "emerges" from a wider set of possibilities resulting in a stochastic, self-organizing representation of marine ecosystems (Fellows et al. 2007) came up repeatedly in discussions of this paper and others. While this approach has not been applied to higher trophic levels in marine ecosystems, it appears to offer an alternative to the constrained and idealized functional groupings employed by Lehodey et al. (this volume). The argument is that, given the wide diversity of possible functional types or species, the best approach is to let the successful functional types or species emerge or evolve within the model. This clearly is an approach that warrants further effort, particularly since it has the potential to capture unexpected blooms of nuisance and noxious forms, and fundamental changes in foodweb structure.

Lehodey et al. (this volume) have provided a way forward in modeling the dynamics of fish species that range over wide areas, approaching a basin scale. Their approach offers a sharp contrast to the coupled biophysical individual based models (IBM) currently used to model the early-life stages of temperate species such as Atlantic cod where individual stocks occupy more restricted geographic areas (e.g. Lough et al. 2006). Between these two poles lies a middle ground with much less detail treatment of foraging and trophic processes than currently incorporated in IBMs, while still capturing the essence of critical processes controlling recruitment and dynamic density-dependent effects. It is likely in this middle ground that the greatest success will be found.

So, what would this middle-ground look like? Certainly treatment of target species would be staged based with greatest detail on critical-life stages and processes, much the same way the "rhomboid approach" advocates greatest detail at the tropic level of interest. These critical stages and processes would likely include acquisition of energy for growth and production of spawning products, and survival of early-life stages. Closure of the full-life cycle and a memory of past performance would be important. Like the Lehodey et al. (this volume) model, this middle ground would incorporate the effects of environmental forcing on production and food availability, but with more explicit treatment of error and uncertainty. One approach to handling uncertainty is to draw parameters or rates from a probability distribution (Bailey et al. 2003). Different probability distributions for a given parameter could be used in different years, seasons, 
or locations depending on physical forcing (wind stress, precipitation, salinity etc.) or the abundance of predators or prey, for example.

Progress on modeling the dynamics of marine populations will be limited without a better understanding of the critical processes and mechanisms underlying their dynamics. This understanding will not come from modeling alone or even from ongoing and proposed observing programs, but also will require a renewed commitment to laboratory and field experimental and process studies. It is the iterative process of hypothesis development, observation, experimentation and modeling, one feeding off and informing the other, that will lead to progress and the predictive or forecasting capability necessary to make informed choices in the face of uncertainty.

While Lehodey et al. (this volume) commendably attempt to link coupled ocean general circulation and biogeochemical models with models of population dynamics, this link largely relies on phenomenonological coefficients. The authors identify energetic scaling as a viable link between the environment and population dynamics. Future mechanistic models describing the energy flow from individuals to populations and communities are likely to increase the predictive power of this modeling framework. These mechanistic models of energy flow will be essential as the interaction of organisms with the environment and each other shifts in changing environments.

\section{Acknowledgements}

The authors would like to thank the IGBP programs IMBER and GLOBEC as well as the Network of Excellence EUR-OCEANS of the European Union's 6th Framework Program for funding the symposium on "Parameterization of Trophic Interactions in Ecosystem Modelling", Cadiz, March 2007, and the meeting conveners for the invitation to participate.

\section{References}

Bailey, K.M., Ciannelli, L., Agostini, VN. 2003. Complexity and constraints combined in simple models of recruitment. In H.I. Browman and S.B. Skiftesvik. The Big Fish Bang. Proc. $26^{\text {th }}$ Ann. Larval Fish Conf pp. 293-301.

Bakun, A. 2006. Wasp-waist populations and marine ecosystem dynamics: Navigating the "predator pit" topographies. Prog. in Oceanogr. 68, 271-288.

Bakun, A., Broad, K. 2003. Environmental 'loopholes' and fish population dynamics: comparative pattern recognition with focus on El Nino effects in the Pacific. Fish. Oceanogr. 12, 458-473.

Brown, J.H., Gillooly, J.F., Allen, A.P., Savage, V.M., West G. B. 2004. Toward a metabolic theory of ecology. Ecology 85, 1771-1789.

Calder, W. A. 1984. Size, function, and life history. Dover Publications, Mineola, New York. 
deYoung, B. Heath, M., Werner, F., Chai, F., Megrey, B. Monfray, P. 2004. Challenges of modeling ocean basin ecosystems. Science. 304, 1463-1466.

Fellows, M.J., Dutkiewicz, S., Grant, S., Chisholm, S.W. 2007. Emergent biogeography of microbial communities in a model ocean. Science 315, 1843-1846.

Jackson, J.B.C., Kirby. M.X. et al. 2001. Historical overfishing and the recent collapse of coastal ecosystems. Science 293, 629-637

Kleiber, M. 1932. Body size and metabolism. Hilgardi 6, 315-353.

Koehl, M.A.R. 1989. From individuals to populations. Pages 39-53 in J. Roughgarden, R. M. May, and S. A. Levin, editors. Perspectives in Ecological Theory. Princeton University Press, Princeton.

Kristiansen T., Fiksen $\varnothing$., Folkvord A. 2007. Simulating early life history of larval Atlantic cod (Gadus morhua): model validation and the role of habitat selection. Can J Fish Aquat Sci 64:136-151

Lehodey, P. Chai, F., Hampton, J. 2003. Modeling climate-related variability of tuna populations from a coupled ocean-biogeochemical-populations dynamics model. Fish. Oceanogr. 12, 483-494.

Lehodey, P., R. Murtugudde, I. Senina, this volume. Bridging the gap from ocean models to population dynamics of large marine predators: a model of mid-trophic functional groups Progress in Oceanography

Lough, R.G., E.A. Broughton, L.J. Buckley, L.S. Incze, K. Pehrson Edwards, R. Converse, A. Aretxabaleta, and F.E. Werner (2006) Modeling growth of Atlantic cod larvae on the southern flank of Georges Bank in the tidal-front circulation during May 1999. Deep Sea Res. II. 53:2771-2788.

Myers, R.A., Baum, J.K., Shepherd, T.D., Powers, S.P., Peterson,C.H. 2007. Cascadingeffects of the loss of apex predatory sharks from a coastal ocean. Science. 315, 1846-1848.

Savage, V.M., Gillooly, J.F., Brown, J.H., West, G.B., Charnov, E.L. 2004. Effects of body size and temperature on population growth. American Naturalist 163, 429 - 441.

Schoener, T.W. 1986. Mechanistic approaches to community ecology: a new reductionism. Integrative and Comparative Biology 26, 81 - 106. 